\title{
Rancang Bangun Alat Untuk Monitoring Parameter Pada Sistem Pemanen Energi Matahari Dengan Model Telemetri Multi Node Menggunakan Komunikasi Serial I2c
}

\author{
Fiqri Ihwanul Falah ${ }^{1}$, Wakhyu Dwiono ${ }^{2}$, Muhammad Taufiq Tamam ${ }^{3}$ \\ Program Studi S1 Teknik Elektro, Universitas Muhammadiyah Purwokerto \\ Fakultas Teknik dan Sains, Universitas Muhammadiyah Purwokerto
}

\begin{tabular}{l}
\hline \hline Informasi Makalah \\
\hline Dikirim, 20 April 2020 \\
Direvisi, 17 Juni 2020 \\
Diterima, 29 Juni 2020
\end{tabular}

\section{Kata Kunci:}

Pemanen Energi Matahari Komunikasi Serial I2C Telemetri

\begin{abstract}
INTISARI
Telemetri adalah penggunaan telekomunikasi untuk mengirimkan sinyal pengukuran secara otomatis dari alat ukur yang berada pada jarak jauh. Dalam pemantauan tidak semua kondisi memungkinkan dilakukan secara langsung dikarenakan terkendali oleh faktor geografis dan jarak sehingga digunakan metode dengan model telemetri. Tujuan dari penelitian ini adalah mewujudkan sistem telemetri menggunakan modul HC-12 dengan komunikasi serial I2C. Perancangan ini terdiri dari perangkat keras (PIC 16F877A, Arduino UNO, LM35, ACS712 30A, Voltage Divider, FTDI 232RS dan Modul HC-12) dan perancangan perangkat lunak dengan Bahasa pemrograman C. Data hasil, dianalisa mengunakan metode grafik dan teori error. Hasil komunikasi serial I2C dapat mengirimkan 20 data sensor secara bergantian dengan baik dengan jarak jangkauan 0,20 meter hingga 4,80 meter. Tegangan keluaran keseluruhan sensor sebanding dengan sensitivitas dan berbanding secara linier terhadap hasil data sensor. Hasil modul HC-12 sebagai telemetri dapat mengirimkan data dengan jangkauan jarak 50 meter data terkirim dengan baik, melebihi jarak tersebut data dapat terkirim namun terdapat noise. Hasil pengukuran data error didapatkan error sensor suhu pada pengujian pertama 1,6\%. Pada pengujian kedua sensor suhu error 1,45\%. Error sensor tegangan pada pengujian pertama 2,75\%. Pada pengujian kedua sensor tegangan error 2,1\%. Error sensor arus pada pengujian pertama 3,05\%. Error pengujian kedua sensor arus 2,95\%.
\end{abstract}

Keyword:

Solar Energy Harvester

Serial Communication I2C

Telemetry

\begin{abstract}
Telemetry is the use of telecommunications to transmit the measurement signals automatically from the measuring device remotely. In monitoring not all possible conditions are done directly due to control by geographic and distance factors, so it used method with telemetry model. The purpose of the study is to manifest telemetry using $\mathrm{HC}-12$ module with serial communication I2C. The design consists of the hardware (PIC 16F877A, Arduino UNO, LM35, ACS712 30A, Voltage Divider, FTDI 232RS and HC12 Module) and software design with the $\mathrm{C}$ programming language. The results of the research were analyzed using graph methods and error theory. In this study serial communication I2C can transmit 20 sensor data alternately well, serial communication I2C have distance range of 0,20 meters until 4,80 meters. The overall output voltage of the sensor is proportional to the sensitivity and linearly proportional to the results of sensor data. The HC-12 module is used as telemetry, based on the testing of this module, it can send data with a range of 50 meters, the data is sent well, exceeds the distance data can be sent but there was noise. The results of the measurement data obtained by temperature sensor error on first testing $1,6 \%$. Second testing error on $1,45 \%$. Voltage sensor error on first testing $2,75 \%$. Second testing error on $2,1 \%$. First testing flow sensor error on $3,05 \%$. Second testing error on $2,95 \%$.
\end{abstract}

Korespondensi Penulis: 
Fiqri Ihwanul Falah

Program Studi S1 Teknik Elektro

Universitas Muhammadiyah Purwokerto

Jl Raya Dukuhwaluh, Purwokerto, 53182

Email: fiqriihwanul22@gmail.com

\section{PENDAHULUAN}

Telemetri adalah penggunaan telekomunikasi untuk mengirimkan sinyal pengukuran secara otomatis dari alat ukur yang berada pada jarak jauh. Kendala pengukuran pada lokasi yang sulit terjangkau dapat diatasi dengan menggunakan metode pengukuran jarak jauh [1]. Sistem telemetri bertujuan untuk mengambil suatu data dari tempat yang lokasinya jauh dan mengirimkannya ke stasiun pusat untuk diolah [2].

Komunikasi serial banyak diaplikasikan sebagai metode untuk monitoring data dari suatu sistem, standar komunikasi yang sering digunakan adalah komunikasi serial UART (Universal Asynchronous Receiver Transmitter). Komunikasi tersebut dapat mengirimkan data dengan jarak yang jauh namun kecepatan pengiriman yang lambat dan hanya dapat mengirimkan data antar satu mikrokontroler saja artinya hanya satu sistem saja yang dapat dimonitoring. Komunikasi serial I2C (Inter Integrated Circuit) dapat mengirimkan data dengan cepat dan dapat mengirimkan data ke beberapa mikrokontroler atau beberapa sistem karena komunikasi ini mempunyai dua perangkat yaitu, perangkat slave dan perangkat master yang masing-masing perangkat dapat dinamai dengan alamat yang unik[3][4]. Untuk sistem dengan model telemetri menggunakan modul wireless $\mathrm{HC}-12$ juga dapat dikatakan jaringan sensor nirkabel yang merupakan sensor pintar, pada masing-masing titik sensornya memiliki kemampuan untuk merasakan keadaan sekitarnya, serta memproses data yang diperoleh dan berkomunikasi [5]. Modul HC-12 menggunakan metode modulasi ASK, dalam proses modulasi ini kemunculan frekuensi gelombang pembawa tergantung pada ada atau tidak adanya sinyal informasi digital. Keuntungan yang diperoleh dari metode ini adalah bit per baud (kecepatan digital) lebih besar [6].

Sistem telemetri pada solar panel yang telah diwujudkan diantaranya adalah menggunakan IOT [7], menggunakan saluran komunikasi serial RS232 [8]. Komunikasi menggunakan terminal UART dapat dilakukan secara full dupleks sehingga komunikasinya menjadi efisien [9]. Aplikasi pengontrolan jarak jauh juga telah diwujudkan menggunakan jaringan RS485 [10]. Namun untuk memaksimalkan sistem telemetri, dalam artikel ini diajukan sistem monitoring pemanen energy matahari menggunakan menggunakan komunikasi serial I2C (Inter Integrated Circuit) agar dapat memantau banyak sistem dan komunikasi UART (Universal Asynchronous Receiver Transmitter) untuk pengiriman data jarak jauh. Variabel yang dipantau dalam sistem pemanen energi matahaari ini adalah nilai suhu, arus dan tegangan panel surya dengan aki sebagai beban.

Metode pengukuran yang digunakan pada penelitian ini adalah pengukuran jarak jauh (telemetri) yang menggunakan modul HC-12 dan komunikasi serial I2C (Inter Integrated Circuit). Sistem tersebut menggunakan tiga mikrokontroler atau multi node, yaitu dua mikrokontroler sebagai node dan satu mikrokontroler sebagai server. Pembacaan data variabel dilakukan melalui dua mikrokontroler node yang kemudian dikumpulkan dan diterima lagi oleh transmitter dari mikrokontroler server dan diterima lagi oleh receiver dengan menggunakan modul HC-12 dengan komunikasi UART (Universal Asynchronous Receiver Transmitter) yang langsung terpasang ke FTDI RS232, kemudian data tersebut dapat dibaca dan ditampilkan pada PC (Personal Computer).

\section{METODE PENELITIAN}

\subsection{Tahap Penelitian}

Untuk mewujudkan sistem monitoring parameter pada sistem pemanen energi matahari dengan model telemetri menggunakan komunikasi I2C (Inter Integrated Circuit) ini dilakukan tahapan-tahapan yang terdiri dari dilakukan yaitu, pada tahapan pertama pembuatan diagram alir sistem, pada tahapan yang kedua pembuatan perangkat keras, pada tahapan yang ketiga pembuatan perangkat lunak dan tahap yang terakhir analisis data.

\subsection{Diagram Alir}

Sistem monitoring parameter pada sistem pemanen energi matahari dengan model telemetri menggunakan komunikasi I2C (Inter Integrated Circuit) ini terdiri dari tiga bagian atau tiga blok yaitu blok satu sebagai input, blok dua sebagai kontrol dan blok tiga sebagai output, masing-masing blok bekerja satu sama lain seperti yang diperlihatkan pada Gambar 1 . 


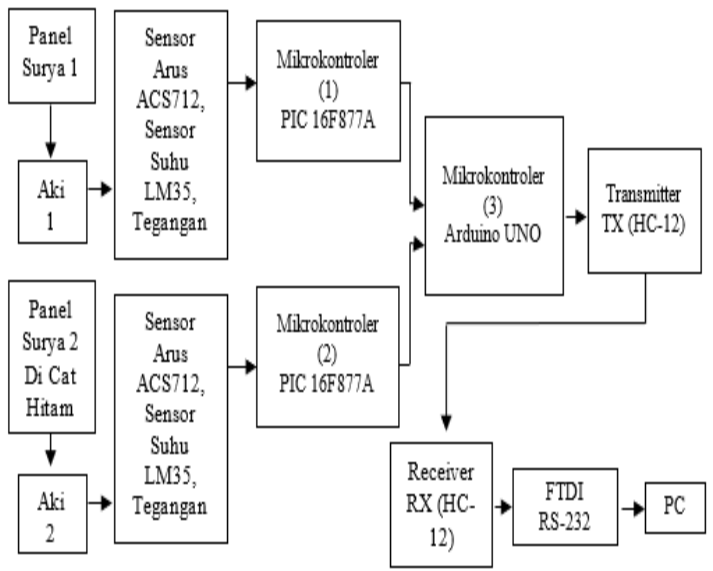

Gambar 1. Diagram Alir Sistem

\subsection{Perancangan Perangkat Keras}

Rangkaian dari perangkat keras sistem monitoring parameter pada sistem pemanen energi matahari dengan model telemetri menggunakan komunikasi I2C (Inter Integrated Circuit) diperlihatkan pada Gambar 2 .

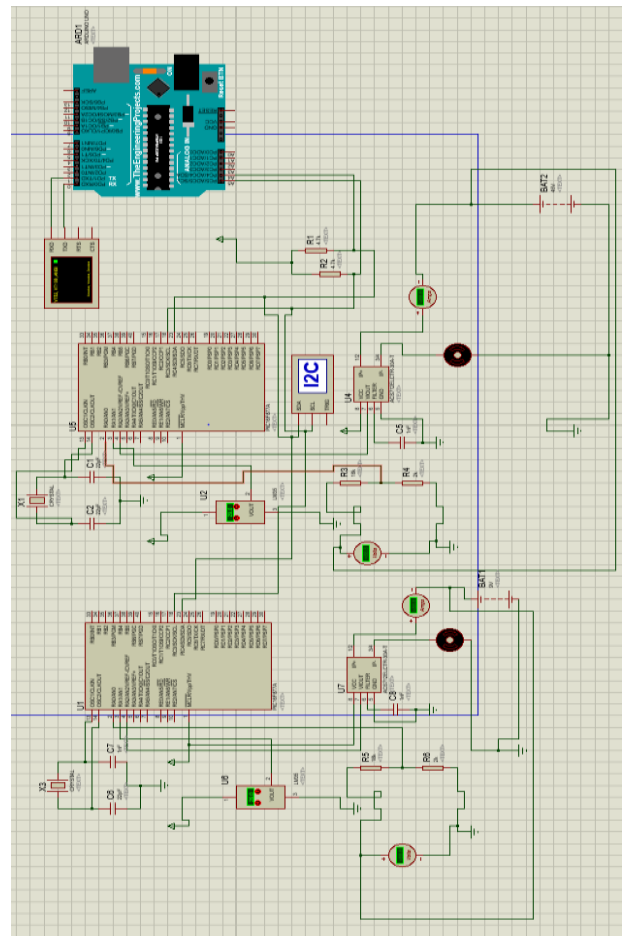

Gambar 2. Rangkaian Sistem

\subsection{Perancangan Perangkat Lunak}

Flow Chart perangkat lunak sistem monitoring parameter pada sistem pemanen energi matahari dengan model telemetri meggunakan komunikasi I2C (Inter Integrated Circuit) dibagi menjadi dua yang diperlihatkan pada Gambar 3 dan 4. 


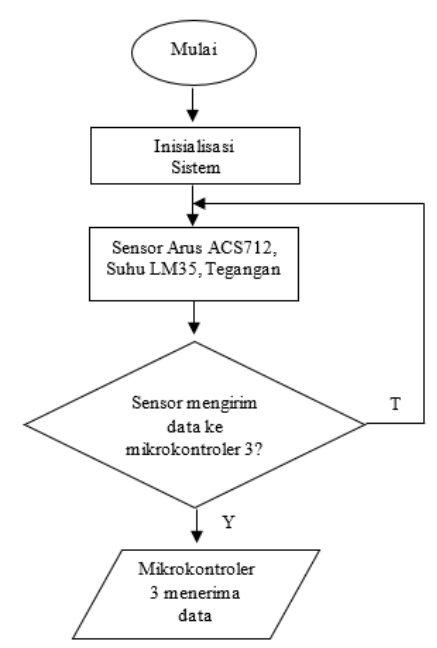

Gambar 3. Flow Chart Mikrokontroler 1 dan Mikrokontroler 2

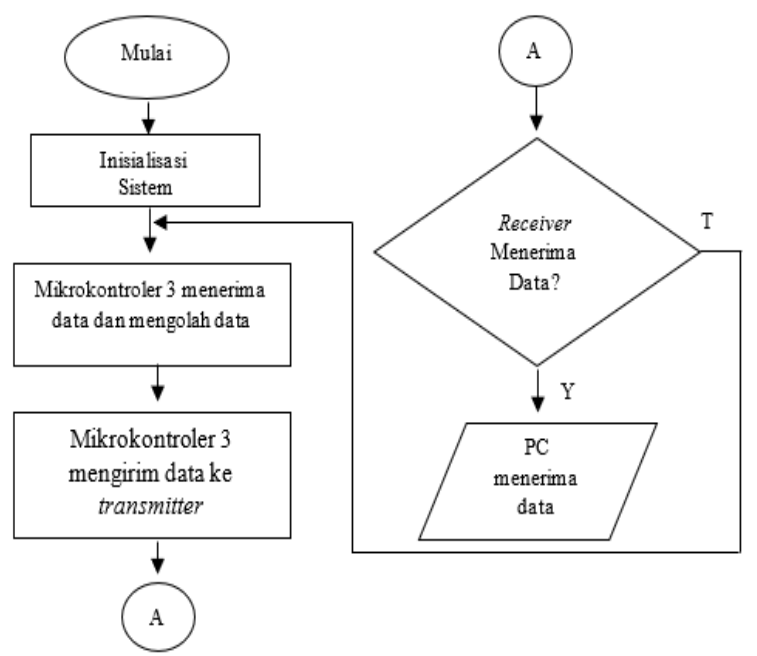

Gambar 4. Flow Chart Mikrokontroler 3

\section{HASIL DAN PEMBAHASAN}

\subsection{Tahap Pengujian}

Sistem monitoring parameter pada pemanen energi matahari dengan model telemetri menggunakan komunikasi serial I2C (Inter Integrated Circuit), diuji kinerjanya dengan menguji beberapa sistem dengan dua kondisi. Kondisi pertama terdapat panel surya dan beban aki dengan sensor suhu, tegangan dan arus. Kondisi kedua hamper sama dengan kondisi pertama, yang membedakan hanya panel surya yang dicat hitam.

\subsection{Pengujian Komponen Sistem}

\subsubsection{Pengujian Sensor Suhu LM35}

Sensor LM35 dimasukan ke dalam tabung yang berisi air sebagai media pengukuran, sebelum sensor LM35 dimasukan ke air, sensor diberi stainless steel casing dan diisolasi sebagai pelindung terhadap air karena sensor LM35 jika terkena air akan mengalami kerusakan. Sensor suhu LM35 dapat mendeteksi nilai suhu $-50^{\circ} \mathrm{C}$ sampai dengan $+150^{\circ} \mathrm{C}$ dan juga dapat dioperasikan pada catu daya $4 \mathrm{~V}-30 \mathrm{~V}$. 


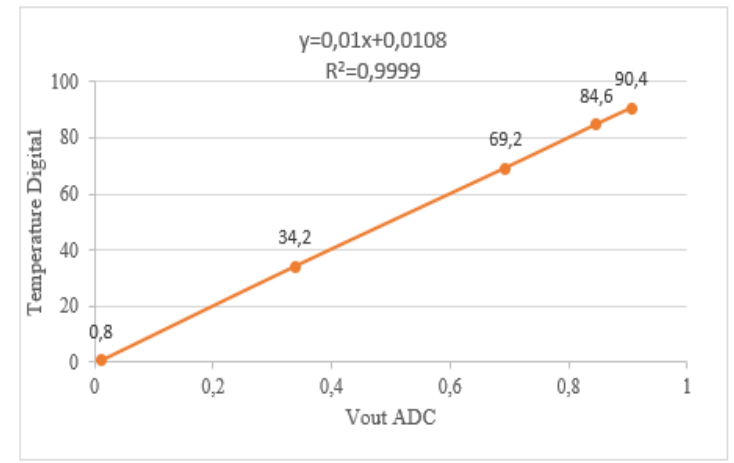

Gambar 5. Grafik Pengujian Sensor Suhu Sistem 1

\subsubsection{Pengujian Sensor ACS712 30A}

Sensor arus ACS712 30A ini memerlukan supply daya sebesar 5V, untuk membaca nilai tengah (nol ampere) tegangan sensor diatur pada 2,5V. sensor ini dapat mendeteksi nilai arus negatif dan positif sebesar 30A sampai dengan 30A, yang setiap arus yang dilalui oleh sensor ini maka terdapat perubahan tegangan pada keluaran sensor. Dalam pengujian sensor ini menggunakan lampu dengan jumlah yang berbeda-beda hingga mencapai arus sebesar 5A, dan dibandingkan dengan ampere meter analog.

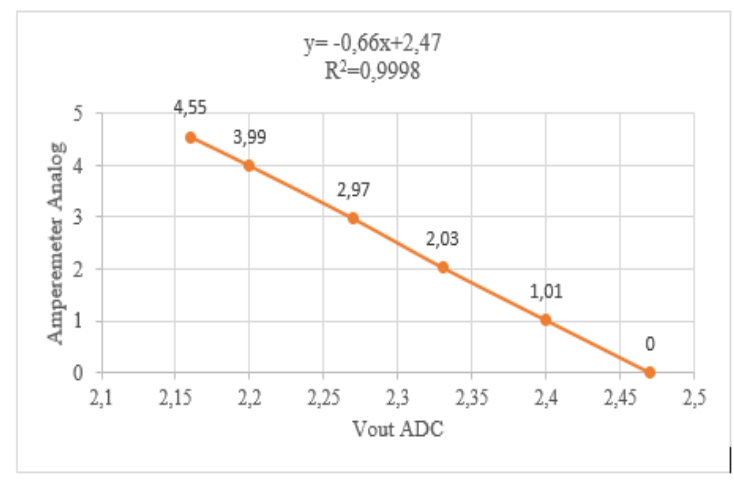

Gambar 6. Grafik Pengujian Sensor Arus Sistem 1

\subsubsection{Pengujian Voltage Divider}

Sensor modul tegangan hanya dapat mendeteksi nilai tegangan DC $0-25 \mathrm{~V}$ jika menggunakan sistem tegangan $5 \mathrm{~V}$ pada mikrokontroler dan hanya dapat mendeteksi nilai tegangan DC 0-16,5V jika menggunakan sistem tegangan 3,3V karena modul sensor tegangan didasarkan pada prinsip penekanan resistansi, dan dapat membuat tegangan input berkurang lima kali dari nilai tegangan asli.

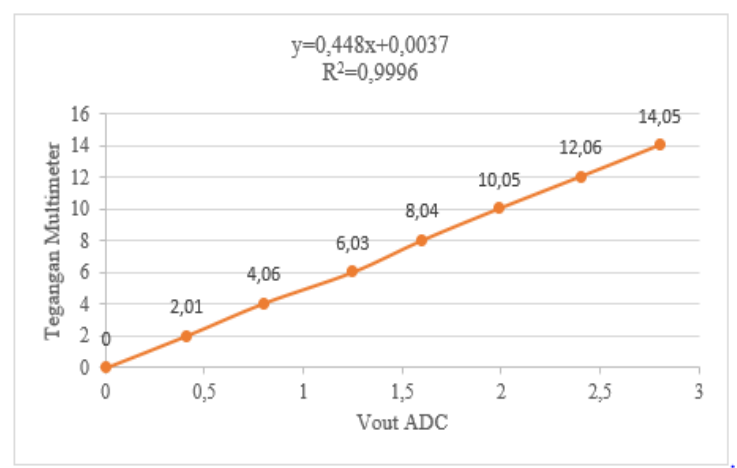

Gambar 7. Grafik Pengujian Sensor Voltage Divider Sistem 1

Dari keseluruhan pengujian data sensor dapat dikatakan keluaran keseluruhan sensor berbanding secara linear dengan kenaikan atau penurunan nilai sensor, dengan nilai koefisien determinasi dari hubungan 
antara tegangan keluaran sensor dengan nilai yang diukur didapatkan rata-rata $\mathrm{R}=0,999$. Hasil ini berarti 99,9\% variasi variabel terikat disebabkan oleh variabel bebas, sehingga keseluruhan sensor dapat digunakan dalam sistem ini.

\subsection{Pengujian Sistem Komunikasi dan Telemetri}

\subsubsection{Pengujian Komunikasi Serial I2C}

Pengujian komunikasi serial I2C dilakukan dengan cara menghubungkan kedua slave (pengirim) ke master (penerima) dengan jarak yang berbeda-beda, dan juga mengambil data sinyal komunikasi I2C untuk melihat prinsip kerjanya. Pada pengujian ini, jarak maksimal yang ditempuh komunikasi serial I2C untuk pengiriman data yang terkirim adalah adalah 0,20 meter sampai dengan 4,80 meter namun dari 20 data yang dikirim kadang terdapat data yang hilang namun setelah mengirmkan data yang hilang, data terkirim dengan baik lagi dengan demikian pada kode program komunikasi serial I2C kurang sempurna sehingga harus disempurnakan. Komunikasi serial I2C tidak dapat mengirimkan data jarak jauh dikarenakan terdapat pull-up resistor dan juga mempunyai dua jalur yang mengirimkan SDA sebagai data dan juga SCL sebagai clock.

\subsubsection{Pengujian Modul HC-12}

Pengujian telemetri menggunakan modul HC-12 dilakukan dengan cara menghubungkan modul HC-12 pengirim yang dipasang pada Arduino UNO dengan modul HC-12 penerima yang dihubungkan dengan FTDI 232 RS yang langsung terhubung oleh PC. Pada pengujian ini jarak maksimal yang ditempuh modul HC-12 dengan pengiriman data yang terkirim dengan baik adalah hingga 50 meter. Modul HC-12 sebenarnya dapat mengirim data hingga satu kilometer menurut data sheet namun karena terdeteksi sedikit halangan serta pengujian pada tempat yang kurang tinggi maka data terdapat banyak noise yang banyak sehingga menyebabkan data tidak dapat terkirim dengan baik. Modul HC-12 terdiri dari TX (Pengirim) dan RX (Penerima) mempunyai frekuensi $433 \mathrm{MHz}$ sampai dengan $473.0 \mathrm{MHz}$ sehingga dapat mengirim dan menerima data dengan baik.

\subsection{Pengujian Sistem Telemetri}

Pada pengujian pengukuran data bertujuan untuk mengetahui hasil perbandingan alat ukur sensor yang telah dibuat dan alat ukur pembanding yang berupa, multimeter digital, ampere meter analog dan suhu digital yang biasa digunakan sebagai alat pengukuran data tersebut secara manual.

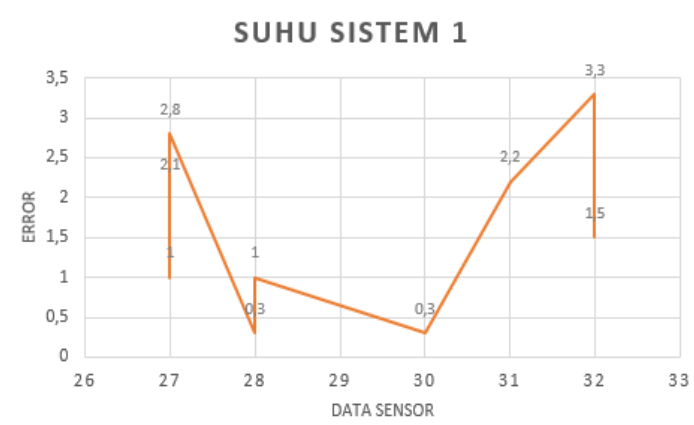

Gambar 8. Grafik Pengukuran Suhu dan Error Sistem 1

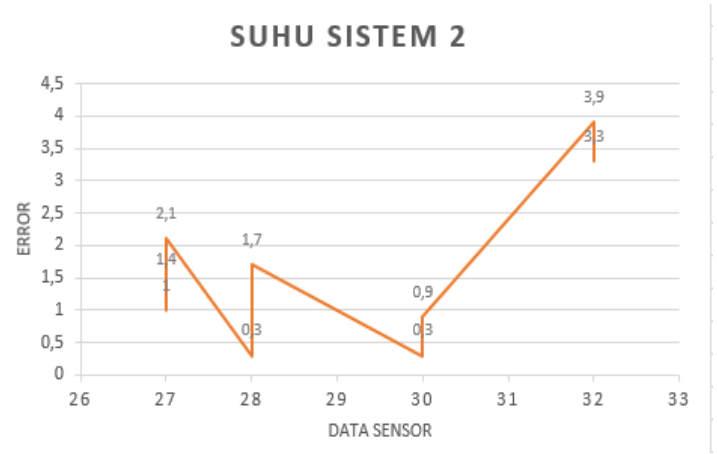

Gambar 9. Grafik Pengukuran Suhu dan Error Sistem 2 


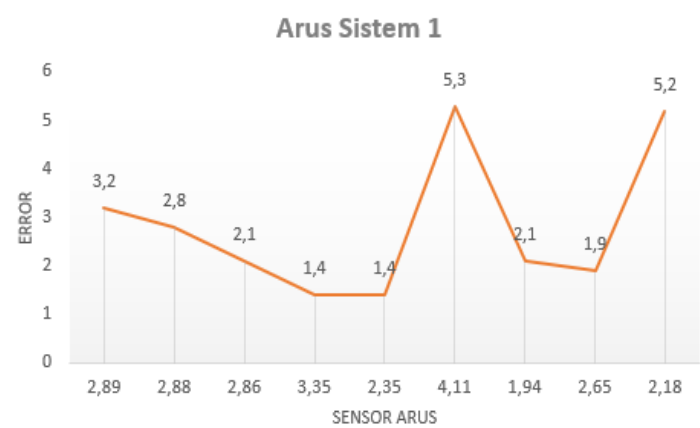

Gambar 10. Grafik Pengukuran Arus dan Error Sistem 1

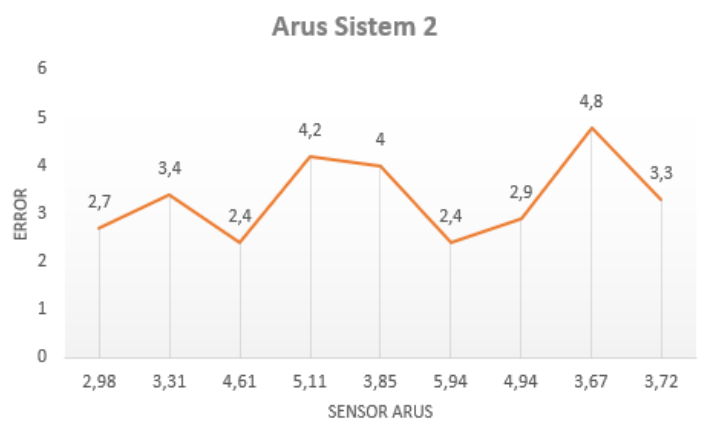

Gambar 11. Grafik Pengukuran Arus dan Error Sistem 2

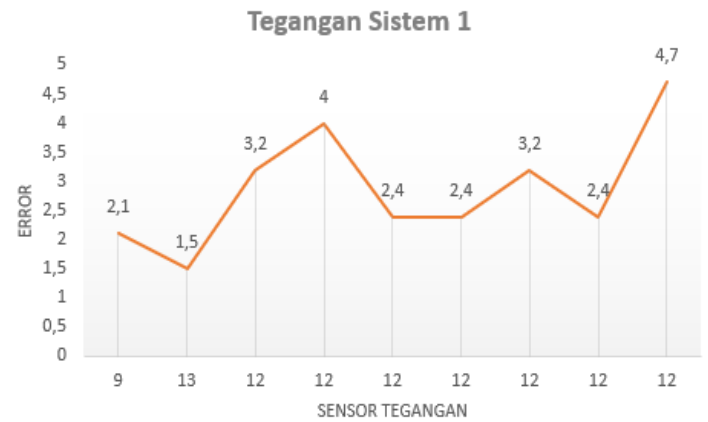

Gambar 12. Grafik Pengukuran Tegangan dan Error Sistem 1

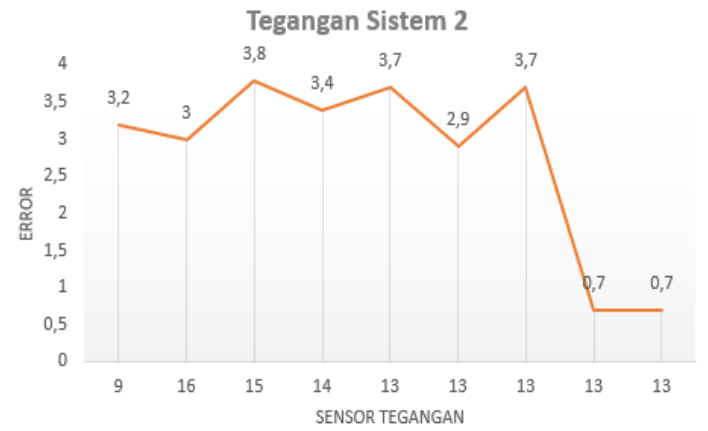

Gambar 13. Grafik Pengukuran Tegangan dan Error Sistem 2

Hasil presentase kesalahan pengukuran tersebut didapat dari beberapa hal sebagai berikut:

a) Komunikasi serial I2C (Inter Integrated Circuit) menggunakan metode itoa (integer to ascii) karena komunikasi serial I2C (Inter Integrated Circuit) hanya dapat mengirimkan data per 8 bit sekali sehingga data yang masuk adalah bilangan bulat dan tidak bisa bilangan pecahan, karena bilangan pecahan 
mempunyai bit yang besar yaitu 32 bit sehingga jika dipaksakan mengirim data per 32 bit sekaligus maka data tidak bisa diterima atau terkirim.

b) Kabel penyambungan sensor yang disambungkan mikrokontroler penyambungannya sedikit longgar dan tidak terlalu merekat sehingga dapat menimbulkan kesalahan pembacaan sensor.

c) Komponen-komponen yang digunakan harus dalam kondisi yang terbaik dan dari jenis yang terbaik. Karena performa komponen akan maksimal bila dalam keadaan kondisi yang terbaik.

a) Intensitas panas matahari dan juga air yang dipompa yang mengaliri panel surya yang cepat berubah nilai suhu dan nilai intensitasnya ketika sudah mendekati siang hari sehingga data suhu, tegangan, dan juga arus tidak dapat mengikuti perubahan data yang datanya sangat berubah dengan cepat.

\section{KESIMPULAN}

Sistem monitoring pemanen energi matahari jarak jauh menggunakan komunikasi serial I2C (Inter Integrated Circuit) menggunakan modul HC-12 sudah berjalan dengan baik, data sensor dari blok mikrokontroler satu dan blok mikrokontroler dua dapat mengirimkan data dengan baik begitupun juga pada blok mikrokontroler tiga dapat menerima data dengan baik sampai dibaca oleh PC menggunakan modul HC12.

\section{DAFTAR PUSTAKA}

[1] Susanto, Heri., Rozeff Pramana., Muhammad Mujahidin. 2013. Perancangan Sistem Telemetri Wireless untuk Mengukur Suhu dan Kelembaban Berbasis Arduino Uno R3 ATMEGA328P dan XBEE PRO. Tanjung Pinang: Universitas Maritim Raja Ali Haji.

[2] Craden F., Jedlicka R., Henry R. 2002. Telemetry Sistems Engineering. Norwood: Artech House Inc.

[3] Wardana, I Nyoman Kusuma. 2016. Inter Integrated Circuit (I2C) sebagai Sistem Komunikasi Multimikrokontroler Menggunakan Platform Arduino dan MATLAB. Jurnal Matrix, Vol. 6.

[4] Jayant M., Chaitali D, Komal T., Madhura K., Prachi S. 2014, Review of I2C Protocol. International Journal of Research in Advent Technology, Vol. 2

[5] Saifudin M dan Lilik Anifah. 2017. Rancang Bangun Sistem Wireless Sensor Network Untuk Sensor Getaran Berbasis Arduino, Jurnal Teknik Elektro. Vol 6 Nomor 3, hal. 147-153

[6] Stallings, William. 2007. Data \& Computer Communications, Eighth Edition. Prentice Hall, New Jersey.

[7] Rohman, Fadlur dan Muhammad Iqbal. 2016. Implementasi Iot Dalam Rancang Bangun Sistem Monitoring Panel Surya Berbasis Arduino. Prosiding SNATIF ke-3. ISSBN: 978-602-1180-33-4. Hal: 189-196

[8] Fachri, Muhammad Rizal., Ira Devi Sara., Yuwaldi Away. 2015. Pemantauan Parameter Panel Surya Berbasis Arduino secara Real Time. Jurnal Rekayasa Elektrika Vol. 11, No. 4, hal. 123-128 ISSN. 1412-4785 e-ISSN. $2252-$ 620x

[9] Dhineshkaarthi, K., Sundar, S., \& Karthikeyan, B. 2016. Full Duplex Bidirectional UART Communication Between PIC Microcontrollers, ARPN Journal of Engineering and Applied Sciences 11(9), 5876-5880.

[10] Salam, Abdus., Mukhidin., Tasma Sucit. 2012. Rancang Bangun Sistem Jaringan Multidrop Menggunakan Rs485 Pada Aplikasi Pengontrolan Alat Penerangan Kamar Hotel. ELECTRANS, Vol.11, NO.2, hal. 1 - 11, ISSN 1412 3762 